\title{
Foot posture in female patients 5 years after breast-conserving surgery: a case-control study
}

\author{
Iwona Głowacka-Mrotek ${ }^{1}$ (1) - Magdalena Sowa ${ }^{2,3} \cdot$ Tomasz Nowikiewicz $^{2,4} \cdot$ Zygmunt Siedlecki $^{5}$. \\ Wojciech Hagner ${ }^{1}$. Wojciech Zegarski ${ }^{2}$
}

Received: 15 August 2017 / Accepted: 10 January 2018 / Published online: 24 January 2018

(c) The Author(s) 2018. This article is an open access publication

\begin{abstract}
Purpose Along with the improvement in the outcomes of breast cancer treatment being observed in the recent years, longterm studies to assess distant adverse effects of the treatment have become increasingly important. The objective of this study was to assess the foot posture in patients subjected to breast-conserving therapy. The assessment was made 5 years after the surgical procedure.

Methods 116 female patients (mean age of 58.75 years) were qualified into a case-control study. Foot posture on the operated breast side (F1) as well as on the contralateral side (F2) was evaluated using a computer-based foot analysis tool as an extension of projection moiré-based podoscopic examination. Comparisons were made for the following parameters: limb load, L—foot length, W—foot width, L/W-Wejsflog index, ALPHA — hallux valgus angle, BETA—little toe varus angle, GAMMA - heel angle, KY - Sztriter-Godunov index, CL-Clarke's angle, HW-heel width.

Results Five years after BCT, patients placed higher load on the foot on the side of the healthy breast $(p=0.0011)$. No statistically significant differences were observed between F1 and F2 with respect to other foot posture parameters $(p>0.05)$. No statistically significant differences were observed in foot posture parameters in patients having undergone BCT + ALND (axillary lymph node dissection) procedure as compared to patients subjected to BCT + SLNB (sentinel lymph node biopsy) procedure $(p>0.05)$.

Conclusions No changes in foot posture were observed in patients 5 years after the BCT procedure. The type of the surgical procedure related to the lymph nodes within the axillary fossa has no effect on changes in foot posture.
\end{abstract}

Keywords Feet $\cdot$ Breast-conserving therapy $\cdot$ Photogrammetric assessment $\cdot$ Adverse effects

Iwona Głowacka-Mrotek

iwona.glowacka@cm.umk.pl

1 Department of Rehabilitation, Collegium Medicum of the Nicolaus Copernicus University in Torun, Bydgoszcz, Poland

2 Department of Surgical Oncology, Collegium Medicum of the Nicolaus Copernicus University in Torun, Bydgoszcz, Poland

3 Department of Laser Therapy and Physiotherapy, Collegium Medicum of the Nicolaus Copernicus University in Torun, Bydgoszcz, Poland

4 Department of Clinical Breast Cancer and Reconstructive Surgery, Oncology Centre-Prof. F. Łukaszczyk Memorial Hospital, Bydgoszcz, Poland

5 Department of Neurosurgery, Collegium Medicum of the Nicolaus Copernicus University in Torun, Bydgoszcz, Poland

\section{Introduction}

Breast cancer is the most common malignant tumor in female patients in the developed countries. The main therapeutic methodology consists of surgery encompassing mastectomy or breast-conserving therapy (BCT), depending on the indications. BCT consists in the excision of a focal lesion along with a margin of tissue not affected by cancer. Irradiation of the breast is an integral element of BCT [1, 2].

Results of randomized clinical studies reveal no differences in long-term treatment outcomes (e.g., overall survival) between patients subjected to BCT or mastectomy [3-5].

Treatment of patients with invasive forms of breast cancer requires verification of axillary lymph nodes. Depending on the baseline stage of the disease, sentinel lymph node biopsy (SLNB) or axillary lymph node dissection is 
required (ALND). Both procedures are associated with the risk of adverse effects $[6,7]$. When the intervention within the axillary fossa is limited to the removal of the sentinel node, the incidence of adverse events is lower in a statistically significant manner. Long-term adverse effects of BCTrelated surgery with axillary lymph node dissection include lymphedema of the upper limb, limited range of motion of the upper limb on the operated breast side, winged scapula, paresthesias, and postural defects $[8,9]$.

The physical and emotional activity of female patients after surgical treatment of cancer is reduced. This may lead to adverse changes within the motor system such as disturbed symmetry of shoulders and reduced range of motion of the upper limb within the shoulder joint (also due to irradiation of the region). These effects may also be due to reflexive pain-avoiding alignment of the limb. Disturbed range of motion within the shoulder joint is experienced by patients having undergone both BCT and mastectomy [10].

As demonstrated by Crosible et al., the asymmetry in shoulder position due to surgery leads to disturbed kinematics of the spine [11, 12]. Individual elements of human motor system are closely related to one another. Strains in one region of the body may be transferred onto other elements. Well-arched feet are an important element of correct body posture. Deformation of feet and the associated pain may result in postural instability and falls. As shown in our previous studies, differences in foot posture may be observed in patients undergoing mastectomy due to breast cancer between the operated and the contralateral side [13].

The objective of this study was to provide answers to the following questions:

- Are there any differences in the foot postures between the foot on the operated breast side and the foot on the contralateral side in patients having undergone BCT?

- Are there any differences in the load on the foot between the operated breast side and the contralateral side in patients having undergone BCT?

- Are there any differences in the foot postures and limb loads between the operated breast side and the contralateral side in patients having undergone BCT + ALND vs. patients having undergone BCT + SLNB?

\section{Materials and methods}

The case-control study was carried out from April through June of 2017 following an approval no. 339/2017 being obtained from the Bioethics Committee of the Nicolaus Copernicus Medical College. Patients included in the study group had undergone surgical treatment for breast cancer at the Oncology Centre in Bydgoszcz in the period between 01.01.2011 and 30.12. 2011 (i.e., patients in whom 5 years had passed from the date of the surgical procedure). A total of 387 breast-conserving surgeries were carried out at our site in the aforementioned period. Following the analysis of medical documentation and qualification of patients on the basis of the inclusion and exclusion criteria as listed above, a total of 230 patients were qualified for the study. The chosen patients were invited by phone to participate in an additional free examination to assess the architecture of feet. Positive response was obtained from 166 patients. After the interview and physical examination (assessment of lymphedema, history of trauma or surgical procedures that might have affected the foot posture, postural defects, intake of balance-affecting drugs), a total of 116 patients were included in the analysis.

Study inclusion criteria-the following patients were included:

- having undergone BCT surgery with sentinel lymph node biopsy (SLNB) or axillary lymph node dissection (ALND) at the Oncology Centre in Bydgoszcz in 2011;

- in the age range of 40-70 years;

- with primary breast cancer;

- who provided informed consent for participation in the study;

- with appropriate physical fitness and no difficulties in walking.

Study exclusion criteria - the following patients were excluded:

- who required the scope of the surgical treatment being extended during the 5 years after the initial surgery to include axillary lymphadenectomy or mastectomy;

- with history of postural defects and trauma that might have affected foot posture;

- with the presence of other cancers;

- with lymphedema detected on examination;

- with mental disorders;

- with intake of drugs affecting the body balance;

- with other severe disorders (ASA class IV).

The study consisted of the sequence of the following elements:

- analysis of medical documentation (clinical staging, histopathological report);

- collection of data on supportive treatment;

- measurement of body mass and height with BMI calculation;

- measurement of the circumference of upper limbs on the operated breast side and on the contralateral side (using a tape measure at three upper limb levels: I $-10 \mathrm{~cm}$ above the lateral epicondyle of the radial bone, II $-10 \mathrm{~cm}$ 
below the lateral epicondyle of the radial bone, IIIwithin the medial part of the metacarpus (excluding the tongue). Edema was defined as at least $2 \mathrm{~cm}$ difference between the circumference of the limb on the operated breast side and the contralateral limb at least one point of measurement;

- dual scales test to determine the load (in kilograms) on the left and the right foot (the test was carried out using two medical scales with the patient simultaneously placing both feet on both scales);

- assessment of the foot posture using a computer-based foot analysis tool as an extension of projection moiré (CQ Electronic)-based podoscopic examination; the assessment method was harmless and non-invasive for patients, who placed their bare feet on the device adopting a relaxed posture; the study lasted about 1 min with the examiner receiving the image of the patient's feet displayed on the computer screen for further analysis of foot posture parameters; the parameters were transferred into an Excel worksheet.

The following foot posture parameters were determined using the chosen equipment:

- foot length (L) in mm,

- foot width (W) in mm,

- the Wejsflog index, L/W, to assess the transverse arch of the foot. The Wejsflog index ranges were defined as high arch (>3.0), normal arch (2.44-3.0), and flat foot $(<2.44)$;

- ALPHA angle (hallux valgus angle) - normal range of $0-9^{\circ}$; values above $9^{\circ}$ are indicative of hallux valgus;

- BETA angle (little toe varus angle) —normal range of $0-5^{\circ}$; values above $5^{\circ}$ are indicative of varus toe;

- heel angle (GAMMA) - measured in degrees $\left(^{\circ}\right)$ to assess the transverse arch of the foot: high $\operatorname{arch}\left(<15^{\circ}\right)$, normal arch $\left(15-18^{\circ}\right)$, flat foot $\left(>18^{\circ}\right)$;

- Sztriter-Godunov index (KY) — measured in degrees $\left(^{\circ}\right)$ to assess the longitudinal arch of the foot: hollow foot $\left(0.00-0.25^{\circ}\right)$, normal foot $\left(0.26-0.45^{\circ}\right)$, fallen foot $(0.46-$ $0.75^{\circ}$ );

- Clarke's angle-measured in degrees $\left(^{\circ}\right)$ to assess the longitudinal arch of the foot: hollow foot $\left(>55^{\circ}\right)$, normal foot $\left(42^{\circ}-54^{\circ}\right)$, fallen foot $\left(20^{\circ}-41^{\circ}\right)$, and flat foot $\left(<20^{\circ}\right)$;

- heel width (HW) in mm;

- area of foot adhering to the ground surface (FA) - in $\mathrm{mm}^{2}$.

Selected parameters were obtained from the image of the left and the right foot displayed on the computer screen. The results were listed and compared.

\section{Statistical analysis}

Statistical analyses were carried out using PQStat statistical package, version 1.6.4.110.

Body mass and BMI before and after surgery were compared using the Student's $t$ test for dependent variables.

Comparisons of foot postures on the operated breast side and the contralateral side as a function of the type of intervention within the axillary fossa was carried out by means of variance analysis for repeated measures (with treatment as the grouping factor and the measurement side as the repeated measure) as well as Tukey's post hoc test.

Differences, distributions, and results in scales categorized according to normative values depending on the measurement side were compared by the Chi square independence test.

Significance was defined as corresponding to the test probability of $p<0.05$, while high significance was defined as corresponding to the test probability of $p<0.01$.

\section{Results}

The mean age of patients qualified to the study was 58.75 years. Out of the total population of 116 patients, 56 surgeries were performed on the left breast, while the remaining 60 surgeries were performed on the right breast of the patient. Sixty patients had undergone breast-conserving therapy with sentinel lymph node biopsy (BCT + SLNB group), while 56 patients had undergone breast-conserving therapy with axillary lymph node dissection (BCT + ALND group).

All patients declared a history of participation in motor rehabilitation classes; 46 patients were rural residents as compared to 70 patients residing in urban areas. Body mass and BMI values measured before surgery (data collected from medical documentation) and 5 years after surgery were compared in the study group. Body mass and BMI values increased significantly 5 years after surgery $(p<0.0002)$. Table 1 presents the detailed clinical characteristics of the study group. All patients testing positive for the presence of estrogen receptors $(\mathrm{ER}+)$ were qualified to hormone therapy (97 patients).

Foot posture was assessed in the study group on the operated breast side-F1, as well as on the contralateral side-F2. Statistical analysis of this group of variables revealed no statistically significant differences for the following parameters: W, L/W, ALPHA, BETA, GAMMA, KY, Clark's angle, HW, FA, WFA. Statistical differences were observed for limb load assessment (with higher load being placed on the foot of the healthy side; $p=0.0011$ ), and $\mathrm{L}$ parameters ( $p=0.0319$, longer foot on the healthy side) (Table 2). 
Table 1 Clinical characteristics of the study group

\begin{tabular}{|c|c|c|}
\hline Variable & Results & \\
\hline Age & $M=58.75, \mathrm{Me}=60.00$, S.D. $=8.79$ & \\
\hline Body weight before surgery & $M=70.42, \mathrm{Me}=69.00$, S.D. $=11.91$ & $t=-3.9197$ \\
\hline Body weight after surgery & $M=73.32, \mathrm{Me}=72.00$, S.D. $=11.90$ & $\begin{array}{l}d f=115 \\
p=0.0002\end{array}$ \\
\hline Height & $M=1.63, \mathrm{Me}=1.64$, S.D. $=0.05$ & \\
\hline BMI before surgery & $M=26.61, \mathrm{Me}=26.08$, S.D. $=4.40$ & $t=-3.9180$ \\
\hline BMI after surgery & $M=27.73, \mathrm{Me}=27.15$, S.D. $=4.50$ & $\begin{array}{l}d f=115 \\
p=0.0002\end{array}$ \\
\hline \multicolumn{3}{|l|}{ Operated side } \\
\hline $\mathrm{L}$ & $56(48.28 \%)$ & \\
\hline $\mathrm{R}$ & $60(51.72 \%)$ & \\
\hline \multicolumn{3}{|l|}{ Procedure type } \\
\hline $\mathrm{BCT}+\mathrm{SLNB}$ & $60(51.72 \%)$ & \\
\hline $\mathrm{BCT}+\mathrm{ALND}$ & $56(48.28 \%)$ & \\
\hline \multicolumn{3}{|l|}{ Menopausal status } \\
\hline Yes & $83(71.55 \%)$ & \\
\hline No & $33(28.45 \%)$ & \\
\hline \multicolumn{3}{|l|}{ ER } \\
\hline$(+)$ & $97(83.62 \%)$ & \\
\hline$(-)$ & $19(16.38 \%)$ & \\
\hline \multicolumn{3}{|l|}{ PR } \\
\hline$(+)$ & $85(73.27 \%)$ & \\
\hline$(-)$ & $31(26.72 \%)$ & \\
\hline \multicolumn{3}{|l|}{ HER2 } \\
\hline$(-)$ & $49(42.24 \%)$ & \\
\hline$(+1)$ & $50(43.10 \%)$ & \\
\hline$(+2)$ & $2(1.72 \%)$ & \\
\hline$(+3)$ & $15(12.93 \%)$ & \\
\hline \multicolumn{3}{|l|}{ Clinical stage } \\
\hline I A & $86(74.14 \%)$ & \\
\hline II A & $22(18.97 \%)$ & \\
\hline II B & $8(6.90 \%)$ & \\
\hline Number of dissected nodes & $M=7.56, \mathrm{Me}=3.00$, S.D. $=8.43$ & \\
\hline Number of affected nodes & $M=1.19, \mathrm{Me}=0.00$, S.D. $=3.23$ & \\
\hline \multicolumn{3}{|l|}{ Supplementary treatment } \\
\hline RTH & $62(53.45 \%)$ & \\
\hline $\mathrm{CHTH}+\mathrm{RTH}$ & $54(46.55 \%)$ & \\
\hline
\end{tabular}

$M$ arithmetic mean, S.D standard deviation, $M e$ median, $B M I$ body mass index, $L$ left, $R$ right, $B C T+S L N B$ breast-conserving therapy + sentinel lymph node biopsy, $B C T+A L N D$ breast-conserving therapy + axillary lymph node dissection, $E R$ estrogen receptor, $P R$ progesterone receptor, $H E R 2$ human epidermal growth factor receptor 2, $R T H$ radiotherapy, $C H T H$ chemotherapy
No significant differences were observed for parameters characterizing the longitudinal and transverse arches of the feet either. In most women, the transverse arch was found to be within normal limits. The analysis of the longitudinal arch revealed hollow foot in most study patients (KY $\mathrm{F} 1=51.72 \% ; \mathrm{KY} \mathrm{F} 2=49.14 \%$ )-Table 3 .

Categorized values of the ALPHA and BETA angles of both feet were analyzed in the study group. No statistically significant differences $(p<0.05)$ were observed for the results. ALPHA angles were normal in $60.34 \%$ of cases. Regardless of the side of the foot, hallux valgus was observed in similar percentages of patients (F1 39.65\%, F2 $37.93 \%$ ). BETA angle assessment revealed varus little toes on the operated breast side in $93.97 \%$ and on the contralateral side in $90.52 \%$ of patients (Table 4 ). 
Table 2 Comparison of foot assessment parameters in the study patients

\begin{tabular}{|c|c|c|c|c|c|c|c|c|}
\hline \multirow[t]{2}{*}{ Tested parameter } & \multicolumn{3}{|l|}{ F1 } & \multicolumn{3}{|l|}{$\mathrm{F} 2$} & \multicolumn{2}{|c|}{ Student's $t$ test } \\
\hline & Mean & Median & $\begin{array}{l}\text { Standard } \\
\text { deviation }\end{array}$ & Mean & Median & $\begin{array}{l}\text { Standard } \\
\text { deviation }\end{array}$ & $t$ & $p$ \\
\hline Foot load & 36.00 & 34.75 & 6.54 & 37.23 & 36.50 & 6.01 & -3.3510 & 0.0011 \\
\hline $\mathrm{L}$ & 224.85 & 227.00 & 12.83 & 225.66 & 227.00 & 12.67 & -2.1726 & 0.0319 \\
\hline W & 86.59 & 86.00 & 6.25 & 87.01 & 88.00 & 6.02 & -0.9067 & 0.3664 \\
\hline Foot L/W & 2.61 & 2.62 & 0.18 & 2.60 & 2.60 & 0.15 & 0.7638 & 0.4466 \\
\hline ALPFA & 8.35 & 7.60 & 5.50 & 8.48 & 7.80 & 5.38 & -0.2760 & 0.7830 \\
\hline BETA & 15.91 & 15.45 & 7.73 & 15.76 & 14.95 & 8.62 & 0.1762 & 0.8604 \\
\hline GAMMA & 15.32 & 15,05 & 2.73 & 15.64 & 15.40 & 4.71 & -0.7354 & 0.4636 \\
\hline KY & 0.27 & 0.20 & 0.24 & 0.29 & 0.30 & 0.25 & -0.5979 & 0.5511 \\
\hline CL & 51.42 & 52.80 & 13.82 & 52.26 & 54.90 & 12.94 & -0.7726 & 0.4413 \\
\hline HW & 51.23 & 51.45 & 4.83 & 51.46 & 51.05 & 5.65 & -0.6747 & 0.5012 \\
\hline FA & 61.79 & 61.50 & 24.49 & 61.98 & 63.00 & 24.40 & -0.1750 & 0.8614 \\
\hline
\end{tabular}

$F 1$ foot on the operated breast side, $F 2$ foot on the contralateral side, $L$ foot length, $W$ foot width, $L / W$ Wejsflog index, ALPHA hallux valgus angle, BETA little toe varus angle, GAMMA heel angle, $K Y$ SztriterGodunov index, $C L$ Clarke's angle, $H W$ heel width, $W F A$ weighted foot area, $p$ calculated probability value

Table 3 Comparison of categorized sizes of the transverse and the longitudinal arch of foot in the study patients

\begin{tabular}{|c|c|c|c|c|c|}
\hline \multirow[t]{3}{*}{ Transverse arch size } & \multicolumn{4}{|c|}{$\mathrm{L} / \mathrm{W}$} & \\
\hline & \multicolumn{2}{|l|}{$\mathrm{F} 1$} & \multicolumn{2}{|l|}{$\mathrm{F} 2$} & \\
\hline & $N$ & $\%$ & $N$ & $\%$ & \\
\hline High arch & 2 & 1.724 & 1 & 0.862 & $\mathrm{Ch}^{\wedge} 2=2.6311$ \\
\hline Normal arch & 93 & 80.172 & 102 & 87.931 & $d f=2$ \\
\hline Fallen arch & 21 & 18.103 & 13 & 11.207 & $p=0.2683$ \\
\hline \multirow[t]{3}{*}{ Longitudinal arch size } & \multicolumn{4}{|c|}{ KY } & \\
\hline & \multicolumn{2}{|l|}{$\mathrm{F} 1$} & \multicolumn{2}{|l|}{ F2 } & \\
\hline & $N$ & $\%$ & $N$ & $\%$ & \\
\hline Hollow & 60 & 51.72 & 57 & 49.14 & $\mathrm{Ch}^{\wedge} 2=0.8816$ \\
\hline Normal & 15 & 12.93 & 17 & 14.65 & $d f=3$ \\
\hline Fallen & 39 & 33.62 & 38 & 32.76 & $p=0.8299$ \\
\hline Flat & 2 & 1.72 & 4 & 3.45 & \\
\hline
\end{tabular}

$F 1$ foot on the operated breast side, $F 2$ foot on the contralateral side, $L / W$ Wejsflog index, $K Y$ Sztriter-Godunov index, $p$ calculated probability value

No statistically significant differences in the postures of both feet were observed in either the BCT + SLNB or the BCT + ALND group $(p>0.05)$ (except for the lower limb load in the BCT + ALND group patients who placed higher load on the foot on the side of the healthy breast $(p=0.042))$. A similar lack of correlation was observed for the results obtained in both of these subgroups $(\mathrm{BCT}+\mathrm{SLNB}$ vs. BCT + ALND)-Table 5.

\section{Discussion}

The study assessed the changes in the load and posture of feet in women having undergone BCT 5 years after the procedure. The analysis revealed that 5 years after BCT, female patients placed higher loads on the side of the healthy breast (statistical significance of $p=0.0011$ for comparison with the operated breast side). The analysis revealed statistically significant differences in foot loads within the BCT + ALND, with higher loads being placed on the healthy feet $(p=0.0422)$. No statistically significant 
Table 4 Comparison of categorized ALPHA and BETA angles in the study group

\begin{tabular}{|c|c|c|c|c|c|}
\hline & \multicolumn{4}{|c|}{ ALPHA } & \multirow[t]{3}{*}{$p$} \\
\hline & \multicolumn{2}{|l|}{$\mathrm{F} 1$} & \multicolumn{2}{|l|}{$\mathrm{F} 2$} & \\
\hline & $N$ & $\%$ & $N$ & $\%$ & \\
\hline $0-9^{\circ}$ & 70 & 60.345 & 72 & 62.07 & $\mathrm{Ch}^{\wedge} 2=0.0726$ \\
\hline \multirow[t]{5}{*}{$>9^{\circ}$} & 46 & 39.655 & 44 & 37.93 & $d f=1$ \\
\hline & & & & & $p=0.7876$ \\
\hline & \multicolumn{4}{|c|}{ BETA } & \multirow[t]{3}{*}{$p$} \\
\hline & \multicolumn{2}{|l|}{$\mathrm{F} 1$} & \multicolumn{2}{|l|}{$\mathrm{F} 2$} & \\
\hline & $N$ & $\%$ & $N$ & $\%$ & \\
\hline $0-5^{\circ}$ & 7 & 6.03 & 11 & 9.48 & $\mathrm{Ch}^{\wedge} 2=0.9637$ \\
\hline$>5^{\circ}$ & 109 & 93.97 & 105 & 90.52 & $\begin{aligned} d f & =1 \\
p & =0.3263\end{aligned}$ \\
\hline
\end{tabular}

$F 1$ foot on the operated breast side, $F 2$ foot on the contralateral side, ALPHA hallux valgus angle, BETA little toe varus angle. $p$ value of calculated probability

Table 5 Comparison of foot postures in the study patients depending on the type of surgical procedure within the axillary fossa lymph node system

\begin{tabular}{|c|c|c|c|c|c|c|c|}
\hline \multirow[t]{2}{*}{ Tested parameter } & \multicolumn{3}{|c|}{$\mathrm{BCT}+\mathrm{SLNB}, n=60$} & \multicolumn{3}{|c|}{$\mathrm{BCT}+\mathrm{ALND}, n=56$} & \multirow{2}{*}{$\begin{array}{l}\text { Comparison F1 vs F3, F2 vs } \\
\text { F4, statistical significance }\end{array}$} \\
\hline & $\begin{array}{l}\text { Foot on oper- } \\
\text { ated side F1, } \\
\text { mean }\end{array}$ & $\begin{array}{l}\text { Foot on contralat- } \\
\text { eral side } F 2 \text {, mean }\end{array}$ & $p$ & $\begin{array}{l}\text { Foot on oper- } \\
\text { ated side F3, } \\
\text { mean }\end{array}$ & $\begin{array}{l}\text { Foot on contralat- } \\
\text { eral side } \mathrm{F} 4 \text {, mean }\end{array}$ & $p$ & \\
\hline Lower limb load & 36.38 & 37.43 & 0.1726 & 35.60 & 37.01 & 0.0422 & $\begin{array}{l}p 1=0.9080 \\
p 2=0.9837\end{array}$ \\
\hline $\mathrm{L}$ & 225.28 & 226.28 & 0.2247 & 224.39 & 225.00 & 0.6735 & $\begin{array}{l}p 1=0.9821 \\
p 2=0.9491\end{array}$ \\
\hline W & 86.75 & 87.33 & 0.7965 & 86.43 & 86.66 & 0.9850 & $\begin{array}{l}p 1=0.9923 \\
p 2=0.9358\end{array}$ \\
\hline $\mathrm{L} / \mathrm{W}$ & 2.62 & 2.59 & 0.7334 & 2.61 & 2.61 & 0.9999 & $\begin{array}{l}p 1=0.9923 \\
p 2=0.9763\end{array}$ \\
\hline ALPHA & 8.62 & 8.88 & 0.9790 & 8.06 & 8.05 & 0.9999 & $\begin{array}{l}p 1=0.9438 \\
p 2=0.8455\end{array}$ \\
\hline BETA & 16.15 & 15.67 & 0.9790 & 15.66 & 15.85 & 0.9987 & $\begin{array}{l}p 1=0.9886 \\
p 2=0.9994\end{array}$ \\
\hline GAMMA & 15.24 & 16.07 & 0.5320 & 15.40 & 15.19 & 0.9866 & $\begin{array}{l}p 1=0.9962 \\
p 2=0.6072\end{array}$ \\
\hline KY & 0.28 & 0.27 & 0.9943 & 0.26 & 0.30 & 0.6764 & $\begin{array}{l}p 1=0.9887 \\
p 2=0.9013\end{array}$ \\
\hline CL & 52.54 & 51.49 & 0.8983 & 50.22 & 53.09 & 0.2584 & $\begin{array}{l}p 1=0.7895 \\
p 2=0.9181\end{array}$ \\
\hline HW & 51.16 & 51.47 & 0.9201 & 51.30 & 51.46 & 0.9899 & $\begin{array}{l}p 1=0.9988 \\
p 2=1.0000\end{array}$ \\
\hline FA & 59.41 & 60.08 & 0.9667 & 64.35 & 64.01 & 0.9958 & $\begin{array}{l}p 1=0.6961 \\
p 2=0.8223\end{array}$ \\
\hline
\end{tabular}

$B C T+S L N B$ group undergoing BCT + SLNB surgery, $B C T+A L N D$ group undergoing BCT + ALND surgery, $F 1$ foot on the operated breast side, $F 2$ foot on the contralateral side, $L$ foot length, $W$ foot width, $L / W$ Wejsflog index, $A L P H A$ hallux valgus angle, BETA little toe varus angle, GAMMA heel angle, $K Y$ Sztriter-Godunov index, $C L$ Clarke's angle, $H W$ heel width, $W F A$ weighted foot area, $p 1$ F1 vs F3, $p 2$ F2 vs F4, $p$ calculated probability value 
differences were observed with respect to the remaining foot posture parameters $(\mathrm{W}, \mathrm{L} / \mathrm{W}$, ALPHA, BETA, GAMMA, KY, CL, HT) between the operated side and the contralateral side. As also demonstrated in the study, the type of surgical procedure within the lymph nodes of the axillary fossa (ALND vs. SLNB) did not lead to any permanent changes in the lower limb loads and postures of the feet on the operated breast side and the contralateral side.

No studies of the impact of BCT on changes in foot posture and lower limb loads could be found in the available bibliographic databases. The comparison of foot posture parameters was carried out at a distant time interval after the completion of surgical treatment-after 5 years of patient follow-up characterized by no recurrences of cancer.

Our study is a contribution to the discussion on the adverse consequences of breast-saving therapy in breast cancer patients. As demonstrated in previous analyses performed at our site, a risk of adverse events exists also in the case of breast-saving surgical procedures. The adverse effects include limited range of motion within the shoulder joint, lymphedema, and postural defects within the sagittal and frontal planes [8, 9, 14]. We were also able to demonstrate a correlation between the number of dissected nodes and the reduction in the range of motion within the shoulder joint as confirmed by other studies $[15,16]$. However, systematic rehabilitation after surgical resection of breast cancer facilitates minimization of the adverse effects of the breast cancer treatment as regards limited range of motion within the shoulder joint or the presence of lymphedema $[17,18]$.

Proper foot posture is an important element ensuring overall postural stability. Foot posture deformations have an impact on reduced mobility and balance disorders. These factors have a direct effect on the increased risk of falls [19]. Foot posture changes with age $[20,21]$. As shown by Canseco et al., foot posture is better in individuals who are in good physical shape and lead an active lifestyle [22]. As shown in previous studies, mastectomy was associated with changes in foot posture [13, 23].

Our studies revealed no changes in foot posture between the operated breast side and the contralateral side. However, a number of deviations from normal foot posture were observed in the study group. The analysis of the longitudinal arch revealed hollow foot on the operated breast side in $51.72 \%$ and on the contralateral side in $49.14 \%$ of study patients. The analysis of hallux valgus angle revealed hallux valgus in more than $1 / 3$ of the study patients. Varus little toe was observed in $93.97 \%$ of the patients on the operated breast side and in $90.52 \%$ of the patients on the contralateral side.

Deformations within the skeletal system develop usually due to wearing inappropriate shoes or as a consequence of age-related changes [24]. Foot posture in women depends on a number of factors such as body mass. Wearing high-heeled shoes has a negative effect on the architecture of feet [25, 26]. Our studies demonstrate the need to introduce exercises to improve proper foot arches similar to these in the postmastectomy rehabilitation program. Rehabilitation activities should include education on proper shoe wearing and foot care.

Yang et al. point to the necessity of diagnosing, monitoring, and treating potential adverse effects regardless of whether the patients had undergone complete axillary lymph node dissection (ALND) or only sentinel lymph node biopsy (SLNB) [10]. Our study to assess the differences in foot postures of patients treated for breast cancer evaluated the distant adverse effects of oncological treatment. The study compared the changes in foot posture in women having undergone surgery for breast cancer depending on the type of intervention within the axillary fossa (ALND vs. SLNB). No statistically significant differences were observed for the assessed parameters $(p>0.05)$.

As shown by the available data, women having undergone either BCT or mastectomy for their breast cancer reduce their everyday activity, which has a negative impact on the motor system and the perceived quality of life [27, 28]. An increase in the body mass is common in women treated for breast cancer, mainly as a consequence of reduced physical activity [29-31]. Supplementary treatment also contributes to mass increase [32]. In our study, we were also able to demonstrate a statistically significant increase in body mass and BMI values of patients compared to the values recorded before surgery ( $p<0.0002)$. A total of 97 patients from the study group were qualified for adjuvant hormone therapy after surgical treatment.

In our study, we demonstrated a statistically significant difference between the load placed on the lower limb on the operated breast side and the load placed on the lower limb on the contralateral side (36.00 vs. 37.23). We also identified statistically significant differences within the BCT + ALND group, with more load being placed by the patient on the lower limb on the operated side $(p=0.042)$.

The differences in the loads placed on lower limbs might be due to the changes in body posture, muscular imbalance, or the lower limb being positioned to avoid pain, particularly as relevant observations were more pronounced in the BCT + ALND group. In previous studies, the difference in the loads placed on the lower limbs was higher in the case of patients after mastectomy 13 .

In our study, we also observed a statistically significant difference in the lengths of the feet on the operated side as compared to the contralateral side $(224.85 \mathrm{~mm}$ vs $225.66 \mathrm{~mm}, p=0.0319)$. This difference may reflect an ontogenetic trait not related to the surgical procedure. 
The presented study has certain limitations, mainly consisting in a quite small population of patients included in the analysis. No evaluation of the architecture of feet before surgery had been performed either. Therefore, to obtain a full perspective on the changes in foot posture in breast cancer patients undergoing breast cancer treatment, a prospective study with an appropriately long clinical observation period should be conducted.

Our study showed that breast conservation treatment causes no adverse changes in foot posture on either the operated breast side or the contralateral side. No adverse effects of the treatment were also observed after a distant time interval following its completion ( 5 years after the surgical procedure). Thus, the well-known saying that "less is better" has been confirmed once again.

\section{Compliance with ethical standards}

Conflict of interest All authors declare no financial or other relationships with commercial entities whose products or services are related to the subject matter in the manuscript, or sociopolitical issues that can cause conflict.

Open Access This article is distributed under the terms of the Creative Commons Attribution 4.0 International License (http://creativecomm ons.org/licenses/by/4.0/), which permits unrestricted use, distribution, and reproduction in any medium, provided you give appropriate credit to the original author(s) and the source, provide a link to the Creative Commons license, and indicate if changes were made.

\section{References}

1. Veronesi U, Zucali R, Del Vecchio M. Conservative treatment of breast cancer with QU.A.R.T. Technique. World J Surg. 1985;9:676-81.

2. Veronesi U, Volterrani F, Luini A, et al. Quadrantectomy versus lumpectomy for small size breast cancer. Eur J Cancer. 1990;26(6):671-3.

3. Fisher B, Anderson S, Bryant J, et al. Twenty-year follow up of a randomized trial comparing total mastectomy, lumpectomy, and lumpectomy plus irradiation for the treatment of invasive breast cancer. N Engl J Med. 2002;347(16):1233-41. https://doi. org/10.1056/NEJMoa022152.

4. Jacobson JA, Danforth DN, Cowan KH, et al. Ten-year results of a comparison of conservation with mastectomy in the treatment of stage I and II breast cancer. N Engl J Med. 1995;332(14):907-91. https://doi.org/10.1056/NEJM199504063321402.

5. Grover S, Nurkic S, Diener-West M, Showalter SL. Survival after breast-conserving surgery with whole breast or partial breast irradiation in women with early stage breast cancer: a SEER database analysis. Breast J. 2017;23(3):292-8. https://doi.org/10.1111/ tbj. 12729.

6. Mansel RE, Fallowfield L, Kissin M, et al. Randomized multicenter trial of sentinel node biopsy versus standard axillary treatment in operable breast cancer: the ALMANAC trial. J Natl Cancer Inst. 2006;98(9):599-609. https://doi.org/10.1093/jnci/djj158.

7. Fleissig A, Fallowfield LJ, Langridge CI, et al. Post-operative arm morbidity and quality of life. Results of the ALMANAC randomised trial comparing sentinel node biopsy with standard axillary treatment in the management of patients with early breast cancer. Breast Cancer Res Treat. 2006;95:279-93. https://doi. org/10.1007/s10549-005-9025-7.

8. Głowacka-Mrotek I, Nowikiewicz T, et al. The assessment of the magnitude of frontal plane postural changes in breast cancer patients after breast-conserving therapy or mastectomyfollow-up results 1 year after the surgical procedure. Pathol Oncol Res. 2016;22(1):203-8. https://doi.org/10.1007/s1225 3-015-9995-7.

9. Głowacka I, Nowikiewicz T, Hagner W, et al. Sagittal plane postural changes in female patients with breast cancer after different surgical techniques. Breast J. 2017;23(1):109-11. https ://doi.org/10.1111/tbj.12697.

10. Yang EJ, Park WB, Seo KS, et al. Longitudinal change of treatment-related upper limb dysfunction and its impact on late dysfunction in breast cancer survivors: a prospective cohort study. J Surg Oncol. 2010;101(1):84-91. https://doi.org/10.1002/ jso.21435.

11. Crosible J, Kilbreath SL, Dylke E, et al. Effect of mastectomy on shoulder and spinal kinematics during bilateral upperlimb movement. Physical. 2010;90(5):679-92. https://doi. org/10.2522/ptj.20090104.

12. Crosible J, Kilbreath SL, Hollman L, et al. Scapulohumeral rhythm and associated spinal motion. Clin Biomech. 2008;23(2):184-92. https://doi.org/10.1016/j.clinbiomec h.2007.09.012.

13. Głowacka-Mrotek I, Sowa M, Siedlecki Z, et al. Evaluation of changes to foot shape in females 5 years after mastectomy: a case - control study. Breast Cancer Res Treat. 2017;163:287-94. https://doi.org/10.1007/s10549-017-4183-y.

14. Hayes S, Rye S, Battistutta D, et al. Upper-body morbidity following breast cancer treatment is common, may persist longer-term and adversely influences quality of life. Health Qual Life Outcomes. 2010;31(8):92. https://doi.org/10.1186/1477-7525-8-92.

15. Levy EW, Pfalzer LA, Danoff J, et al. Predictors of functional shoulder recovery at 1 and 12 months after breast cancer surgery. Breast Cancer Res Treat. 2012;134:315-24. https://doi. org/10.1007/s10549-012-2061-1.

16. Langer I, Guller U, Berclaz G, et al. Morbidity of sentinel lymph node biopsy(SLN) alone versus SLN and completion axillary lymph node dissection after breast cancer surgery: a prospective Swiss multicenter study on 659 patients. Ann Surg. 2007;245:452-61. https://doi.org/10.1097/01.sla.0000245472 .47748 .

17. Chan DN, Lui LY, So WK. Effectiveness of exercise programmes on shoulder mobility and lymphoedema after axillary lymph node dissection for breast cancer: systematic review. J Adv Nurs. 2010;66(9):1902-14. https://doi.org/10.111 1/j.1365-2648.2010.05374.

18. Box RC, Reul-Hirche HM, Bullock-Saxton JE, Furnival CM. Physiotherapy after breast cancer surgery: results of a randomized controlled study to minimise lymphoedema. Breast Cancer Res Treat. 2002;75:51-64.

19. Brooke-Wavell K, Perrett LK, Howarth PA, Haslam RA. Influence of the visual environment on the postural stability in healthy older women. Gerontology. 2002;48(5):293-7. https://doi. org/10.1159/000065252

20. Hart ES, de Asla RJ, Grottkau BE. Current concepts in the treatment of hallux valgus. Orthop Nurs. 2008;27(5):274-80. https:// doi.org/10.1097/01.nor.0000337276.17552.

21. Golightly YM, Hannan MT, Dufour AB, Jordan JM. Racial differences in foot disorders and foot type. The Johnston County Osteoarthritis Project. Arthritis Care Res. 2012;64(11):1756-9. https://doi.org/10.1002/acr.21752. 
22. Canseco K, Long J, Smedberg T, et al. Multisegmental foot and ankle motion analysis after hallux valgus surgery. Foot Ankle Int. 2012;33(2):141-7. https://doi.org/10.3113/FAI.2012.0141.

23. Drzał-Grabiec J, Rachwał M, Walicka-Cupryś K. The shape of feet in women after mastectomy. Complement Altern Med Sci. 2013;2(2):123-6.

24. Kuo AD, Speers RA, Peterka RJ, Horak FB. Effect of altered sensory condition on multivariate descriptors of human postural sway. Exp Brain Res. 1994;122:185-95.

25. Snow RE, Williams KR, Holmes GB Jr. The effects of wearing high heeled shoes on pedal pressure in women. Foot Ankle Int. 1992;13(2):85-92.

26. Nyska M, McCabe C, Linge $\mathrm{K}$, Klenerman L. Plantar foot pressures during treadmill walking with high-heel and low-heel shoes. Foot Ankle Int. 1996;17(11):662-6. https://doi.org/10.1177/10711 0079601701103.

27. Nesvold IL, Reinertsen KV, Fosså SD, Dahl AA. The relation between arm/shoulder problems and quality of life in breast cancer survivors: a cross-sectional and longitudinal study. J Cancer Surviv. 2011;5(1):62-72. https://doi.org/10.1007/s11764-010-0156-4.
28. Levangie PK, Santasier AM, Stout NL, Pfalzer L. A qualitative assessment of upper quarter dysfunction reported by physical therapists treated for breast cancer or treating breast cancer sequelae. Support Care Cancer. 2011;19(9):1367-78. https://doi. org/10.1007/s00520-010-0959-x.

29. Battaglini CL, Mihalik JP, Bottaro M, et al. Effect of exercise on the caloric intake of breast cancer patients undergoing treatment. Braz J Med Biol Res. 2008;41(8):709-15.

30. Luctkar-Flude M, Groll D, Woodend K, et al. Fatique and physical activity in older patient with cancer, a six-month follow-up study. Oncol Nurs Forum. 2009;36(2):194-202.

31. Irwin ML, Crumley D, McTiernan A, et al. Physical activity levels before and after a diagnosis of breast carcinoma: the health, eating, activity, and lifestyle (HEAL) Study. Cancer. 2003;97:1746-57.

32. Demark-Wahnefried W, Peterson B, Winer E, et al. Changes in weight, body composition, and factors influencing energy balance among premenopausal breast cancer patients receiving adjuvant chemotherapy. JCO. 2001;19(9):2381-9. 